\title{
Wear Your Bicycle Helmet!
}

Keywords: Brain injury - traumatic, bicycle helmets, head trauma, neurotrauma, outcomes research, prevention

doi:10.1017/cjn.2015.242

Can J Neurol Sci. 2016; 43: 3-4

Bicycle helmets have been shown to be effective in preventing head, brain, and facial injuries to cyclists. ${ }^{1,2}$ Although some authors have argued against the efficacy of helmets, ${ }^{3,4}$ published systematic reviews ${ }^{5,6}$ and a meta-analysis ${ }^{7}$ have demonstrated that helmets protect cyclists from head injuries. A re-analysis in 2011, which included more recent studies and adjustment for potential sources of bias, confirmed the protective effect of bicycle helmets on head injuries and facial injuries. ${ }^{8}$ In the province of Quebec, there is no legislation on bicycle helmet use. In a case-control study involving 129 cycling deaths, an association was found between dying as a result of sustaining a head injury and not wearing a helmet. 9

In the present issue, Dagher et al. retrospectively reviewed 128 patients who presented to the Montreal General Hospital between 2007 and 2011 with bicycle related injuries. Twenty five percent of the patients (18-83 years of age) were apparently helmeted; however, it is not known in what capacity the helmet was actually worn, whether or not it was worn properly, or if the helmet was actually an adequate helmet (ie., helmet's age, state and certification). The authors went on to compare the 32 patients who were assigned to have had a helmet to 96 patients who were not identified to have been wearing a helmet. Even with the discordance in the numbers of the two groups, some important findings were identified. The authors found that the patients who did not have a helmet where more likely to be less educated, single, unemployed and significantly younger compared with the helmet group. In addition, the no helmet group had worse brain computed tomogram findings (2.8 times more likely to have a worse Marshall classification on admission), were more likely to require neurosurgery and had a six fold increased risk of a prolonged intensive care unit stay. Thus, with the limitations of such a study, the authors illustrated the increased morbidity associated with not wearing a helmet while cycling. They recommended that public health initiatives should be targeted to young, single men, the less educated, the unemployed, as well as include efforts to educate the elderly population due to their increased risk of death following traumatic brain injuries (TBI).

The study has inherent limitations, such as its retrospective nature and the small number of patients that were in the helmet group (32) versus the no helmet group (96). This is an obvious selection bias that may influence the results due to the three-fold disparity. Although it is assumed that a more even distribution may strengthen the validity of the results, this remains unknown.

Public Health initiatives such as the ones suggested by the authors are not the only strategies to prevent bicycle-related injuries. Other measures include environmental modifications such as separate lanes on the roadway for cyclists and measures that target drivers of motor vehicles rather than cyclists.

Promotional strategies used to increase bicycle helmet use include a combination of education, subsidy and legislation. For example, bicycle helmet legislation that has been introduced and evaluated in Australia, Canada, New Zealand and the United States has been associated with a decrease in bicycle-related head injuries. ${ }^{10-13}$ Of the three studies included in a systematic review examining changes in head injury risk pre- and post-legislation, two showed a statistically significant reduction in risk and one a non-statistically significant reduction in risk. ${ }^{14}$

In Canada, the first provinces to have legislation mandating all-age bicycle helmet use were British Columbia, New Brunswick and Nova Scotia between 1995 and 1997. Ontario made helmets mandatory for cyclists $<18$ years of age in October of 1995 and Alberta in May of 2002. An all-age mandatory helmet law was introduced in Prince Edward Island in 2003. Manitoba introduced legislation for mandatory helmet use in May of 2013 for individuals $<18$ years of age. Effective April 1, 2015, all cyclists in Newfoundland and Labrador have been required to wear a bicycle helmet. Northwest Territories, Nunavut and Yukon have no bicycle helmet legislation. In Quebec and Saskatchewan there are education programs available. ${ }^{15}$ Saskatchewan is presently considering bicycle helmet legislation.

Dagher et al. identified that were no negative medical outcomes associated with wearing a bicycle helmet in their series. There was a paradoxical increased risk of polytrauma in this group, which may imply that the patients in the helmeted group who presented to the hospital were admitted more so for injuries other than TBI; however, the injury severity scores were similar in both groups. Overall, the helmet group had less trauma changes on brain imaging, shorter length of intensive care unit stays and less neurosurgical interventions. Of the nine deaths, eight were not wearing a helmet at the time of the accident and all died directly as a result of the severe brain injury. The authors also identified four adult patients from the coroner's office who died from TBIs in the same study period, and all four were not wearing bicycle helmets.

In summary, in addition to the increased morbidity and mortality of not wearing a helmet in bicycle related trauma, Dagher et al. outlined higher risk characteristics related to age, education and socioeconomic status that can be associated with a worse outcome. As such, more attention can be paid to individuals with high risk characteristics during hospital admissions and during health promotion initiatives. In this respect, Public Health and programs both at the community and national levels, such as ThinkFirst or Parachute Canada play important roles in head injury prevention. 


\section{DisCLOSURES}

Michael Vassilyadi does not have anything to disclose.

Michael Vassilyadi

Childrens Hospital of Eastern Ontario - Neurosurgery, Ottawa

Ontario, Canada

E-mail: vassilyadi@cheo.on.ca

\section{REFERENCES}

1. Rivara F, Thompson DC, Patterson MQ, Thompson RS. Prevention of bicycle-related injuries: helmets, education, and legislation. Annu Rev Public Health. 1998;19:293-318.

2. Thompson RS, Rivara FP, Thompson DS. A case-control study of the effectiveness of bicycle safety helmets. $\mathrm{N}$ Engl J Med. 1989;320:1361-6.

3. McCarthy M. Do cycle helmets prevent serious head injury? Cycling without helmets. BMJ. 1992;305:881-2.

4. Hillman M. Cycle Helmets: The Case for and Against. London, United Kingdom: Policy Studies Institute; 1993.

5. Thompson DC, Rivara FP, Thompson R. Helmets for preventing head and facial injuries in bicyclists. Cochrane Database Syst Rev. 2000;(2):CD001855.

6. Henderson M. Bicycle Helmet Effectiveness: A Review. Australia: Motor Accidents Authority of New South Wales; 1995.

7. Attewell RG, Glase K, McFadden M. Bicycle helmet efficacy: a metaanalysis. Accid Anal Prev. 2001;33:345-52.
8. Elvik R. Publication bias and time-trend bias in metaanalysis of bicycle helmet efficacy: A re-analysis of Attewell, Glase and McFadden, 2001. Accid Anal Prev. 2011;43: 1245-51.

9. Persaud N, Coleman E, Zwolakowski D, Lauwers B, Cass D. Nonuse of bicycle helmets and risk of fatal head injury: a proportional mortality, case-control study. CMAJ. 2012;184: E921-E923.

10. Cameron MH, Vulcan AP, Finch CF, Newstead SV. Mandatory bicycle helmet use following a decade of helmet promotion in Victoria, Australia-an evaluation. Accid Anal Prev. 1994;26:325-37.

11. Schreiber RA, Kresnow MJ, Sacks JJ, Pledger EE, O’Neil JM, Toomey KE. Effect of a state law on reported bicycle helmet ownership and use. JAMA. 1996;276:1968-73.

12. Scuffham P, Alsop J, Cryer C, Langley JD. Head injuries to bicyclists and the New Zealand bicycle helmet law. Accid Anal Prev. 2000;32:565-73.

13. LeBlanc JC, Beattie TL, Culligan C. Effect of legislation on the use of bicycle helmets. Can Med Assoc J. 2002;166:592-5.

14. Macpherson A, Spinks A. Bicycle helmet legislation for the uptake of helmet use and prevention of head injuries. Cochrane Database Syst Rev. 2008;(3):CD005401. DOI:10.1002/14651858. CD005401.pub3.

15. Hagel BE, Yanchar NL, Canadian Paediatric Society, Injury Prevention Committee. Bicycle helmet use in Canada: The need for legislation to reduce the risk of head injury. Paediatr Child Health. 2013;18:475-80. 